\title{
The Monetary-Fiscal Policy Debate and the Andersen-Jordan Equation
}

\author{
Dallas S. Batten and Daniel L. Thornton
}

ERHAPS Andy's most important and lasting contribution to the economics profession was his research with Jerry Jordan that resulted in the publicaIion of the Andersen-Jordan $(A-J)$ equation or, as it is more widely known, the St. Louis equation. Almost immediately, the two found their work the subject of intense criticism and controversy - much of which continues, though in tones that are significantly muted.'

While the criticisms of Andersen-Jordan were focused on various technical and applied econometric aspects of their work, they were motivated, in large part, by A-J's conclusion that monetary policy has a significant and lasting effect on nominal GNP and that fiscal policy has no lasting effect. These results conflicted sharply not only with the conventional wisdom about the relative effects of monetary and fiscal policy actions but with the results of large-scale econometric models of the lime.

The purpose of this paper is to review the criticisms that emerged following the publication of the $A-J$ equation.: We note that many, if not all, of the criticisms of the $A-J$ paper apply equally well to the vast majority of published research, then and now. More importantly, using the original A-J data, we find no evidence to support these criticisms.

Dallas $S$. Batten and Daniel L. Thomton are research officers at the Federal Reserve Bank of St Louis. Rosemarie V. Mueller provided research assistance.

'The monetary-fiscal policy debate was actually initiated prior to Andersen-Jordan (1968) by Friedman and Meiseiman (1963). Just as the ensuing debate surrounding Fredman and Meiselman's results was waning, however, Andersen and Jordan appeared, rekindling and intensifying the disagreement over the relative efficacy of monetary and fiscal policies.

While our review differs from recent ones by McCallum (1986) and Meyer and Rasche (1980), it is necessary to traverse some of the ground they covered.

\section{1

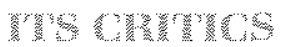

Recently, Cooley and LeRoy (1981) have argued that a close correspondence tends to exist between the advocacy of a theory and the results of scientific investigation. It is not surprising, therefore, that when two known and vocal proponents of monetarism reported empirical results that strongly supported monetarist propositions, the results were received with skepti cism, which was intensified by their use of a single, "reduced-form" equation. Critics were suspicious that A-I inadvertently had either misspecified the model or used faulty econometric techniques to obtain their results."

Three majox criticisms emerged following the publication of the A-J equation. First, it was argued that the equation was misspecified because important exogenous, right-hand-side variables had been excluded. Second, critics claimed that A-J's use of ordinary least squares (OLS) had resulted in simultaneous equation bias. Finally, it was asserted that $A-J$ had failed to identify the relevant exogenous indicators of monetay and fisca policy actions. In addition, critics were concened that the $A-J$ results were sample-specific or not robust to various econometric modifications, including their use of Almon's (1965) polynomial distributed lag estimation technique. The perception that $A-J$ had somehow erred was enhanced when de Leeww and Kalchbrenner (1969), Silber (1971) and Schmid and Waud (1973) tried unsuccessfully to replicate the

${ }^{3}$ A number of critiques appeared very shortly after the publication of the A-J paper, e.g., de Leeuw and Kalchbrenner (1969), Davis (1969), Corrigan (1970), and Goldfeld and Blinder (1972). 
A-J results. 'The following sections examine these criticisms.

\section{W}

The charge that A-J had misspecified their equation by onitting important variables, other than monetary and fiscal policy variables, was leveled by numerous commentators. To understand this argument, consider the original $A-J$ equation:

(1) $\Delta Y_{i}=\alpha+\sum_{i=0}^{3} \beta_{i} \Delta M_{i \cdots i}+\sum_{i=0}^{3} \gamma_{i} \Delta \mathrm{H}_{4-i}+\mathrm{u}_{1}$,

where $Y, M$ and $E$ denote nominal GNP, the money stock (M1) and nominal high-employment government expendifures, respectively, and $u_{1}$ denotes the usual random disturbance term." This equation can be written more compactly as:

(2) $\Delta Y_{1}=\alpha+\beta\left(L_{1}\right) \Delta M_{1}+\gamma(L) \Delta H_{1}+L_{1}$,

where $\beta(L)$ and $\gamma(L)$ are polynomials in the lag opera-

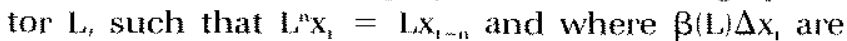
distributed lags of a finite order $k$." A-J chose $k=3$.

If a relevant exogenous policy variable, $Z_{1}$, is omitted, the true specification is not equation 2 , but

(3) $\Delta Y_{1}=\alpha+\beta(L) \Delta M_{1}+\gamma(L) \Delta E_{1}+\delta(L) \Delta Z_{4}+\varepsilon_{1}$,

in which case the error term in equation 2 is $u_{1}=$ $\delta(L) \Delta Z_{1}+E_{z}$. Furthemore, estimates of the monetary and fiscal policy responses from equation 2 will be biased if $\Delta Z_{1}$ is correlated with $\Delta \mathrm{M}_{\sharp}$ or $\Delta \mathrm{E}_{1}$.

This criticism of the A-J equation, while potentially damaging if valid, applies equally well to virtually all

4f now appears that these differences resulfed from differences in programming of in the imposition of polynomial restrictions. Batten and Thornton (1985) have replicated the A-J resuts to the second or third decimal place. Even though other researchers may have been unable to replicate the A-J results exactly, their studies generally supported the qualitative findings of A-J.

The original A-J paper also contained specifications with the adjusted monetary base as the indicator of monetary policy actions and a distributed lag of high-employment government revenues as an additional right-hand-side variable. Equation 1 is the most commonly estimated form of the equation, however.

Futhermore, following an exchange between Friedman (1977) and Carison (1978), the equation was specified in growth rates of the variables. It is interesting to note that A-d also estimated a growth-rate specification, but only reported the first-difference results. For the most part, the issues discussed below are independent of the specification.

The notation used here is the same as employed by McCalum (1986). applied econometric research, including most largescale, simultaneous-equation econometric models of the A-J vintage." Moreover; although it was commonly atgued that the A-J equation was potentially misspecified, econometric theory does not suggess that it is more susceptible to the resulting bias than other estimated equations. Indeed, there was no evidence that their results were biased since no tests tor misspecifcation were petormed.

While their results provided no evidence that the A-J equation is misspecified, Modigliani and Ando (1976) presented evidence from a Monte Carlo-style experiment that led some to doubt the validity of the $A-I$ results. Using artificial data generated by the MPS econometric model, they used a St. Louis-style equation to estimate the reduced-form parameters. The results indicated that the St Louis-style equation produced poor estimates of the "true" monetary and fiscal multipliers, seriously overstating the size of the monetary influence and underestimating the magnitude of the fiscal policy effect. They concluded that the $A-J$ reduced-form estimation technique yielded unreliable estimates.

This conclusion, however, is unwarranted." If a

7For example, Duesenberry et al. (1965).

8 See McCallum (1986), p. 17 and footnote 16.

McCalum (1986) criticized the Modigliani-Ando results by arguing that they faited to distinguish between reduced-form and "finalform" multipliers. He considers the case where $\Delta Z_{\mathrm{t}}=\mathrm{a}_{0}+\mathrm{a}_{1} \Delta \mathrm{Y}_{\mathrm{i}-\mathrm{s}}$ $+\mathrm{a}_{2} \Delta M_{t-1}+\mathrm{a}_{3} \Delta E_{1-1}+\varepsilon_{2}$. Substituting this expression into equa tion 3 yields the following: $\Delta Y_{t}=\alpha+\beta^{\prime}(L) \Delta M_{i}+\gamma^{\prime}(L) \Delta E_{t}+\varepsilon_{t}$ where the coefficients are defined to conform, e.g., $\beta^{\prime}(\mathrm{L})$. $\left[1-\mathrm{La}_{3} \delta(\mathrm{L})\right]^{-1}\left[\beta(\mathrm{L})+\mathrm{La}_{2} \delta(\mathrm{L})\right]$. In contrast to the finite order distributed lags of the A-J equation 2 , the distributed lags on this final-form equation are of ar infinite order. Also, the error term of the A-J equation, $u_{i}$, is hypothesized to be white noise, while that of the above equation, $E_{t}^{t}$, is an intinite order AA process under the assumption about $u_{t}$. The distinction between reduced-and final-form equations may not be important, however, because if the lags of the final-form equation are truncated to match those of equation 2 , these equations are indisting uishable save the error structure. While this difference will attow one to distinguish between the two equa tions, it will only do so if one is willing to make strong claims about the underlying distribution of $U_{\text {. }}$ (McCallum notes this; see p. 24 , footnote 8).

It is interesting to note, however, that our results obtained by adding a distributed lag of $\Delta Y$ to the A-J equation support McCal. Ium's idea that the A-J results reflect all of the direct and indirect effects via lagged values of nominal GNP. A-s and Darby (1976) argued that the equation captured direct and indirect effects via other contemporaneous endogenous variables.

McCallum also argues correctly that "it is hard to imagine any important macroeconomic variabte that is truly exogenous..." (p. 13). If there are reatly no exogenous vatiables, however, then the true reduced form would be a Sims-type VAR model where the only exogenous vartables woutd be the policy and, perhaps, other innovations. 
structural model is well defined with additive, normally distributed errors, consistent estimates of the reduced-form parameters can be obtained by the use of indirect least squares, a la $A-J$." Because the MPS model does not necessarily reflect the true structure of the U.S economy (for example, it ignores potentially important sources of crowding out throwgh wealth effects and Ricardian equivalencel, the ModiglianiAndo experiment cannot be a criticism of the $A-J$ results or of the $A-J$ methodology." Consequently, the Modiglian-Ando evidence is predominantly a statement about Keynesian vs. monetarist views of the world." Furthermore, they provide no general information concerning the usefulness of the reducedform estimation. By design, the A-J equation did not conform to the reduced form of the MPS model; so it is not surprising that the parameter estimates were poor. The experiment merely reminds us that, if one estimates a reduced form that is known to be misspecified, the results may be biased.

\section{W}

Except for the usual checks for serial correlation and heteroskedasticity, the A-J equation was not subjected to formal tests of model specification. Gordon (1976) came closest to lesting the A-J equation for misspecification. He added a set of "omitted variables," $Z$, to the St. Louis equation. Claiming that these variables were nonstochastic, he tested for their statistical significance and measured the impact of these variables on the A-J equation simply by observing whether they affected the size and statistical significance of the estimated long-run monetary and fiscal multipliers. Unfortunately, the Z-variable he constructed - the sum of net exports, consumer expenditures on new automobiles and nonresidential fixed investment was arguably mofe endogenous than the money and

\footnotetext{
1anique estimates of the structural parameters cannot be oblained however, unless the system is exactly identified.

Klein (1976), p. 50, noted in his tiscussion of the Modigliani-Ando paper, "If the world were constructed along lines portrayed by the MPS model, St. Louis conclusions could have been innocently obtained by one who did not bother to estimate the structure. This is the strongest statement that can be made."

${ }^{12}$ Gordon (1976) chides Schwartz (1976) for missing the point of the Modigliani-Ando critique because she criticizes the specification of the MPS model. But this is exacty the point. Gordon later states incorrectly that "the major contribution of the paper is its demonstration that the correlation between irctuded policy variables and other excluded variables severely biases the estimated St, Louis multipliers and renders useless the reduced form fechnique" (p. 60)
}

expenditure variables that $A-J$ had used. Hence, Gordon's results, while by and lange favorable to A-J, say Ittle about whether $A-J$ 's results were affected by specification error: ${ }^{3}$

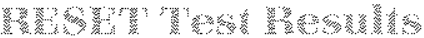

Ideally, one should test the specification of a model by comparing it with a well-specified alternative. Since the reduced form of the MPS model (or any other large-scale Keynesian model) is well specified, it could, in principle, be used as the alternative in a test of the A-J equation. Unfortunately, most large-scale models have too many exogenous variables for the reduced fom to be estimated directly. Even if it could be estimated directly, however, it would be difficult to obtain a data set that is comparably dated with the original A-J data.

This has prompted us to use a general test of misspecification, the RESET test of Ramsey and Schmidt (1976), which requires no additional data. The RESET test is a general diagnostic test for various types of misspecifications, including onitted variables, where the altemative hypothesis is not well specified. ${ }^{14}$ Applied to equation 2 , the F-statistic calculated according to the Ramsey-Schmidt version of the RESET test is .52 , which is not significant at the 5 percent level. ${ }^{i .}$ Hence, the RESET test provides no support for claims that the original $A-J$ equation was misspecified because $A-J$ had omitted significant exogenous variables from their analysis.

"Gordon performed no formal tests. He noted merely that, when his $Z$-variable was included, the sum of coefficients on $\Delta \mathrm{M}$ became smaller and, during one short period, was insignificant. (This period is the one for which the correlation between $\Delta M_{1}$ and $\Delta M_{1} \ldots$ and his composite variable is the highest.) There was no discussion, however, of the problem of multicolinearity or possible bias induced by including variables that are clearly endogenous. (If these extraneous variables do not belong in the model, the estimates are consistent but may be biased in small samples.)

${ }^{14}$ In general, if an equation is misspecified, the residuals will have a non-zero mean. The RESET test is designed to detect a non-zero mean of the residuals. The test is performed by adding $\Delta \hat{\gamma}^{2}, \Delta \hat{\gamma}^{3}, \ldots$, $\Delta \hat{Y}^{h}$ as additional regressors to equation 2 and testing the hypotheses that these regressors have no joint effect on the dependent variable. The test here was performed for $h=2,3,4$; the result with the lowest significance level (in this case, $h=3$ ) is reported. See Fomby, Hill and Johnson (1984), pp. 411-12, for a discussion of the RESET test.

15 When $A-J$ originally estimated equation 2 , they used restricted least squares in the form of Almon's (1965) polynomial distributed lag estimation technique. We have recently shown, however, that none of the important conclusions of A-j depend on these restrictions [Batten and Thornton (1985)]. Consequently, all of the empirical results reported here are obtained with OLS. 


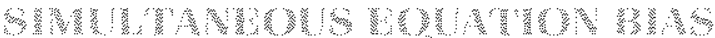

A number of critics argued that the A-J jesults were unreliable because their policy valiables were not strictly exogenous. Because of their knowledge of the issues surrounding targets and indicators of monetary policy, A-J were acutely aware of the need to select exogenous indicators of policy. Indeed, they considered a broad range of measures of monetary and fiscal actions that had been cited fiequently in the literature." In their analysis, they assumed that all excluded variables either were independent of monetary and fiscal actions or were influenced by them, so that monetary and fiscal policies exerted an indirect effect on the economy through these factors. ${ }^{\prime-~} \mathrm{~A} J$ reasoned that if monetary and fiscal influences were not independent of other factors, the constant term, which they argued summarized the impact of these factors, would have changed as these variables changed. Using a Chow test to test whether the parameters of their equation were temporally stable, they found no evidence of instability.

Given the attention that $A-J$ gave to this issue, it is odd that their work was singled out as subject to simultaneous equation bias, when a number of works of applied economics of this vintage were not criticized for applying oLs to equations with right-handside variables that were more clearly endogenous."

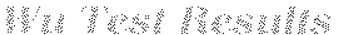

Again, despite claims that the $A-J$ results were questionable on grounds of simultaneity, svstematic lesting for simultaneous equation bias has been sparse. McCallum (1986) compared OLS and instrmmental variables (IV) estimates of the A-J equation, but performed no formal tests. Extending McCallum's analysis, we perform a $W u(1973)$ test using the original $A-J$ data. Like McCallum, we used three lags of $\Delta \mathrm{M}, \Delta \mathrm{F}$ and the three month Treasury bill rate as instruments for $\Delta \mathrm{M}_{1}$ and $\Delta \mathrm{F}_{\mathrm{q}}$. The results are reported in table 1 .

${ }^{16}$ Both Andersen and Jordan participated in a Conference on Indicators and Targets of Monetary Policy held at UCLA in 1966. Andersen contributed to the conference proceedings; see Andersen (1969).

17 This possibility was also considered by McCallum (1986) and Darby (1976), though MoCallum included a lagged dependent variable to obtain his distinction between the reduced form and the finat form; see footnote 9 above.

180ne of the most important of these was Chow's (1966) pathbreaking work on money demand, in which current values of real GNP and a nominal interest rate appeared on the right-hand side of the equation.

\section{Table 1}

\section{OLS and IV Estimates of the} Andersen-Jordan Equation

\begin{tabular}{|c|c|c|}
\hline Variable & OLS & IV \\
\hline Constant & $\begin{array}{c}2.311^{*} \\
(2.82)\end{array}$ & $\begin{array}{l}2.548^{*} \\
(2.45)\end{array}$ \\
\hline$\Delta M_{i}$ & $\begin{array}{l}2.121 \\
(2.87)\end{array}$ & $\begin{array}{c}0.676 \\
(0.33)\end{array}$ \\
\hline$\Delta M_{1}$ & $\begin{array}{l}0.312 \\
(0.32)\end{array}$ & $\begin{array}{c}1.652 \\
(0.84)\end{array}$ \\
\hline$\Delta M_{t^{\mu} 2}$ & $\begin{array}{l}2.696^{\star} \\
(2.69)\end{array}$ & $\begin{array}{r}2.005 \\
(1.56)\end{array}$ \\
\hline$\Delta M_{-3}$ & $\begin{array}{l}0.671 \\
(0.87)\end{array}$ & $\begin{array}{l}0.452 \\
(0.51)\end{array}$ \\
\hline$\Sigma \Delta M_{1}$ & $\begin{array}{l}5800^{\circ} \\
(7.34)\end{array}$ & $\begin{array}{c}4.785^{*} \\
(3.68)\end{array}$ \\
\hline$\Delta E_{1}$ & $\begin{array}{r}0.379 \\
(1.40)\end{array}$ & $\begin{array}{r}1300 \\
(146)\end{array}$ \\
\hline$\Delta E_{1-1}$ & 0.523 & $\begin{array}{r}0.315 \\
(0.81)\end{array}$ \\
\hline$\Delta \mathrm{E}_{\mathrm{t}, \mathrm{z}}$ & $\begin{array}{l}0.022 \\
(0.08)\end{array}$ & $\begin{array}{r}0.217 \\
(0.54)\end{array}$ \\
\hline$\Delta E_{i}$ & $\begin{array}{c}-0.763^{*} \\
(2.95)\end{array}$ & $\begin{array}{l}0.832^{\star} \\
(2.81)\end{array}$ \\
\hline$\Sigma \Delta E_{t}$ & $\begin{array}{l}0.161 \\
(0.52)\end{array}$ & $\because \begin{array}{c}0.566 \\
(1.17)\end{array}$ \\
\hline Joint Frtest, $\Delta \mathrm{M}$ & $15.84^{*}$ & $8.65^{*}$ \\
\hline Joint F-test, $\Delta E$ & $3.17^{*}$ & $2.75^{*}$ \\
\hline$\overline{\mathbf{R}}^{2}$ & 0.61 & 0.54 \\
\hline DW & 1.747 & 2.010 \\
\hline $\mathrm{SE}$ & 3.96 & 4.42 \\
\hline
\end{tabular}

"Indicates statistical significance at the 5 percent level.

Absolute vatue of $t$-ratio in parentheses

A comparison of OLS and IV estimates shows some large differences, particularly for the coefficients on $\Delta \mathrm{M}_{1}$ and $\Delta \mathrm{F}_{4}$. The IV estimates show a smaller initial effect of money and a larger initial effect of government expenditures relative to the OLs estimates. Nevatheless, the $\mathrm{Wu}$ test chi-square statistic is 20 , not statistically significant at the 5 percent level.

It is not too surprising that the $\mathrm{W}$ estimates are relatively imprecise. The first-stage $\bar{R}^{2}$ s were .54 and .38 for $\Delta \mathrm{M}_{1}$ and $\Delta \mathrm{E}_{1}$, respectively. Moreover, the fact that three lags of $\Delta M_{1}$ and $\Delta E_{1}$ are used as instruments means that $\Delta \hat{M}_{1}$ and $\Delta \hat{E}_{\mathrm{E}}$ are likely to be highly colrelated with the other regressors of the A-J equation. While the test could be carred out with altemative instruments, there is no obvious guide to their selecfion. In any event, it is unlikely that the results will be 
Table 2

\section{Estimates of an Autoregressive Version of the Andersen-Jordan Equation}

\begin{tabular}{|c|c|c|}
\hline Varable & Coeffotent & tratlo \\
\hline Constant & 2464 & (258) \\
\hline$\Delta \mathrm{M}_{1}$ - & 2049 & $(284)$ \\
\hline$\Delta M_{+}$ & 0206 & $(0,2)$ \\
\hline$\Delta M_{1}$ & 297 & $(208)$ \\
\hline$\Delta N_{1}-3$ & 0399 & $(045)$ \\
\hline$\geq \Delta M_{1}$ & 5213 & $(5,1)$ \\
\hline$\Delta E$ & 0277 & $(097)$ \\
\hline$\Delta E_{n}$ & 0.638 & 2,27 \\
\hline $\mathrm{AE}_{2}$ & 0025 & $(0,09)$ \\
\hline $\mathrm{dE}_{\mathrm{n}}$ & -100 & $280)$ \\
\hline $\mathrm{sE}$ & 0231 & $(066)$ \\
\hline 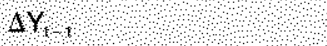 & 0250 & $(186)$ \\
\hline $4 \mathbf{l}_{2}$ & 10184 & $1(52)$ \\
\hline $4 \mathrm{Un}_{3}$ & 10030 & $(0,26)$ \\
\hline 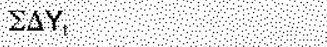 & 0026 & $(015)$ \\
\hline 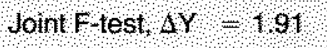 & & \\
\hline Jometest $\triangle M$, $959^{\prime}$ & & \\
\hline Jom $F, e s, \triangle F, 300$ & & \\
\hline 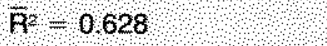 & & \\
\hline $0 w=2146$ & & \\
\hline$S E-387$ & & \\
\hline
\end{tabular}

Absolute value of trato

Indcates significance at be 5 percent level.

convincing unless they are robust over a broad choice of instruments. It can only be said that, based on the insfruments used, there is no evidence of simultaneous equation bias in the $\mathrm{A}-\mathrm{J}$ equation.

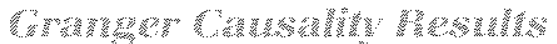

There is additional evidence that the $A_{-}$l results were not affected by simultaneous equation bias. Simultaneity requires temporal feedback between money and income. Thus, the lack of Granger (1969) causality from income to money is a necessary, though not sufficient, condition for statistical exogeneity." When Elliot (1975) performed tests of Granger causality between money, income and govenment expenditures, he found unidirectional causality run-

${ }^{19}$ See Wu (1983) for a discussion of these issues. ning from money to income and bidirectional causality between expenditures and income." More recently, using the original $A-J$ data, Baten and Thornton (1985) found unidirectional causality running from money to income and no causal ordering between income and expenditures.

The fact that income does not Granger-cause money implies that the coefficients on the distributed lag of $\Delta M_{1}$ do not reflect the feedback of income on itself via money; instead, these coefficients measure the direct, and possibly indirect, effects of money on the economy. To verify this interpretation, a threequarter distribtuted lag of $\Delta Y$ was included in the $A-J$ equation as separate regressors and the significance of these coefficients was tested. The results are reported in table 2. The coefficients on the lags of the depen" dent variable are not significantly different from zero - individually or jointly, Furthermore, the coefficients on the money and expenditure variables differ little from the OLS results of table 1.

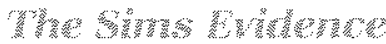

Although his criticism was not directed explicity at the $A-J$ equation, Sims $(1980,1982)$ has argued recently that the impact of monetary policy actions is very small if interest rates are included in the same equation." To investigate Sims' conjecture, we added a contemporaneous and three-quarter distributed lag of the change in the three-month ${ }^{\circ}$ Treasury bill rate $(\Delta \mathrm{TB})$ to the $A-J$ equation. "The results, reported in table 3 , show that only the contemporaneous coefficient on $\Delta \mathrm{TB}$ is significant. Moreover, the coefficients on the money and expenditure variables are little changed from those in table 1 , and none of the qualitative conclusions about the effectiveness of monetary or fiscal policy actions is altered.

Thus, as was the case for allegations of misspecification, there is considerable disparity between the conventional wisdom and the empirical results conceming the issue of simultaneity. Nevertheless, the claim that simultaneity is a serious problem for the $A$ equation is a deeply ontrenched and widely accepted

\footnotetext{
20 Entt used Sirms (1972) procedure which requires that the data be filtered, a process that can affect the test restils. See Feige and Pearce (1979).

${ }^{21}$ McCallum $(1983,1986)$ has critiqued Sims' results on theoretical grounds.

22The equation was asso estimated with the level of the Treasury bill rate; however, none of the qualitative conclusions were changed.
} 
criticism of their work." The evidence examined in this section, however, suggests that estimation of the original $\mathrm{A}-\mathrm{J}$ equation was not affected by simultaneity.

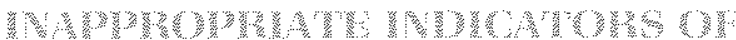

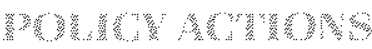

A third major criticism of the St. Louis equation was that A-J's indicators of policy actions may be inappropriate. Failure to use appropriate indicators could bias the estimated parameters, perhaps by distorting the relative importance of monetary and fiscal actions. ${ }^{3 . t}$

In a sense, this argument is an extension of the policy endogeneity argument since its proponents contended that the appropriate indicator of monetary policy should not respond endogenously to forces outside of the Fed's control. For example, in the first published criticism of A-J, de Leeuw and Kalchbrenner (1969) criticized the use of the monetary base land implicitly M1) as an indicator of monetary policy actions on the grounds that some of its components (particularly, currency and borrowed reserves) were endogenous and not controlled by the Fed directly. Instead, de Leeuw and Kalchbrenner offered an alternative exogenous policy measure that they obtained by subtracting currency and borrowings from the adjusted monetary base. When they estimated an A-J type equation using their measure of monetary policy actions, they found the cumulative monetary policy multiplier was much smaller than that of the $A-J$ equation and not significantly different from zero. On the other hand, their estimated cumulative government spending multiplier was substantially larger and was statistically significant..$^{\text {si }}$

In their reply, A-J (1969) pointed out that de Leeuw and Kalchbrenner's focus on the uses of the monetary base was inappropriate. Although the banks and the public determine the uses of the base, the Fed controls the size of the monetary base through its influence over the sources of the base, the largest component of

\footnotetext{
${ }^{23}$ While Andersen and Jordan acknowiedged that money could be endogenously related to income and expenditure variables via a "Fed reaction function," they considered this to be of little practical significance. See Andersen and Jordan (1969), p. 16.

${ }^{24}$ For some, the concern was that some of the effect of fiscal policy might be incorrectly attributed to monetary policy. See Binder and Solow (1874).

25This tine of argument was also taken by Gramtich (1971).

${ }^{26}$ Government receipts were also included; the estimated cumblative multiplier of government receipts also increased but was statistically significant only with longer lags.
}

\section{Table 3}

\section{Estimates of the Andersen-Jordan Equation with a Distributed Lag of Interest Rates}

\begin{tabular}{|c|c|c|c|}
\hline Lags & $\Delta M$ & $\Delta T B$ & $\Delta E$ \\
\hline 0 & $\begin{array}{c}2.409^{*} \\
(3.07)\end{array}$ & $\begin{array}{c}4.216^{*} \\
(2.37)\end{array}$ & $\begin{array}{c}0.313 \\
(1.17)\end{array}$ \\
\hline$\because \quad \therefore$ & $\begin{array}{r}-0.633 \\
(0.61)\end{array}$ & $\begin{array}{r}0.122 \\
(0.06)\end{array}$ & $\begin{array}{c}0.639^{*} \\
(2.32)\end{array}$ \\
\hline 2 & $\begin{array}{r}2.124 \\
(2.00)\end{array}$ & $\begin{array}{c}0.199 \\
(0.10)\end{array}$ & $\begin{array}{c}0.002 \\
(0.01)\end{array}$ \\
\hline 3 & $\begin{array}{l}0.737 \\
(079)\end{array}$ & $\begin{array}{r}0.122 \\
(0.07)\end{array}$ & $\begin{array}{c}0666^{*} \\
(2.47)\end{array}$ \\
\hline sum & $\begin{array}{l}4.637^{*} \\
(4.95)\end{array}$ & $\begin{array}{r}4.415 \\
(1.39)\end{array}$ & $\begin{array}{l}0.228 \\
(0.94)\end{array}$ \\
\hline Constant & $\begin{array}{c}2.910^{\circ} \\
(3.47)\end{array}$ & & \\
\hline Joint $F$-test, $\Delta M=7,65^{\circ}$ & & & \\
\hline Joint F-test, $\Delta \mathrm{TB}=1.96$ & & & \\
\hline $\begin{array}{l}\text { Joint } F \text {-test, } \Delta E=3.10^{*} \\
\bar{A}^{2}=635\end{array}$ & & & \\
\hline $\mathrm{DW}=1.78$ & & & \\
\hline $\mathrm{SE}=3.83$ & & & \\
\hline
\end{tabular}

*Indicates statistical significance at the 5 percent level Absolute value of the t-ratio in parentheses

which is the Fed's holdings of U.S. govemment securi ties. Thus, the Fed determines the size of the monetary base through its sales or purchases of govemment securities

Furthemore, A-J noted that changes in the $M 1$ money stock during their estimation period were dominated by changes in the monetary base. Hence, the fed exercised control over M1 through its control of the sources of the monetary base. Since this exchange, the disagreement over the measurement of monetary policy actions has subsided, and the monetary base and M1 land, at times, broader monetary aggregates) are genemally accepted, and commonly used, as indicators of policy actions.

A-J's measurement of fiscal policy actions was criticized more than their measure of monetary policy actions. Recognizing that certain components of both federal govemment expenditures and revenues rem spond endogenously to the level of economic activity, A-J utilized high-employment measures, which were adjusted for these influences. De Leetw and Kalch- 
brenner contended that this adjustment was incomm plete because it failed to eliminate the influence of inflation. The substitution of inflation-adjusted, highemployment government expenditures and revenues, however, had little impact on the estimated parameters of the equation.

Gramlich (1971) felt that the non-monetary "exogenous" influences were too nartowly defined. Consequently, he constructed two boader composite measures. His expenditure measure was government purchases plus exports, grants-in-aid and an inventory adjustment for defense purchases. His revenue measure included high-employment personal taxes plus interest payments and social security contributions less exogenous transfers that is, all tansfers except unemployment compensation). While these changes did result in larger land more nearly statistically significant sums of estimated coefficients for the non-monetary influences, the general results of A-J remained intact.

Comigan (1970) offered what appeared to be the most damaging criticism of the highemployment measures of fiscal policy actions. He argued that they did not represent applopriate indicators of discretionary fiscal policy actions, since high-employment measures (especially revenues) would change with high-employment income. In their place, he offered his initial stimulus (IS) measure of discretionary changes in fiscal policy. The IS measure of govemment expenditures did not differ significantly fron the highemployment measure. The Is measure of revenues, on the other hand, differed considerably from its high employment counterpart. In particular, the is measure of a change in government revenues was nonzero only in quarters in which a lax was introduced, modified, suspended or eliminated.

When IS measures were substituted for highemployment measures in an A-J type equation, the results were starting: the estimated cumulative impact of changes in M1 declined, while those of both changes in government expenditures and of changes in government revenues rose significantly and, more importantly, were apparently statistically significant ${ }^{2:}$ Thus, Corrigan concluded that fiscal policy actions had a meaningful impact on nominal economic activity.

\footnotetext{
${ }^{27}$ Corrigan did not report $t$-statistics or standard errors for the summed coefficients. Assuming that the estimated coefficients are uncorrelated, one obtains a t-statistic of 3.0 for testing the hypothesis that the $\mathrm{\Sigma} E=0$ and a $\mathrm{t}-\mathrm{statistic}$ of 9.46 for testing that $\mathrm{\Sigma T}=0$. Both of those are statistically significant at the 5 percent level.
}

Subsequently, however, Schmidt and Waud (1973) found that Corrigan's results depended critically on the polynomial restrictions he imposed When these restrictions, which appeared to be rejected by the data, were relaxed, Schmidt and Waud obtained results with the IS measures that were similar to A-J's.

The evidence suggests that $A-J$ 's results concerning the effect of fiscal policy were not critically dependent on their measurement of monetary or fiscal policy actions. Meyer and Rasche (1980) summarized their investigation of this issue by noting that, "the modifications suggested ... have not generally resulted in dramatic changes in the estimated multiplies in simple reduced-form equations." $"$ "

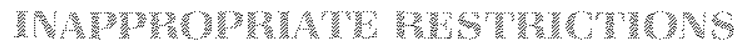

To estimate their dynamic specification, A-J used Almon's (1965) polynomial distributed lag estimation technique that was designed to improve the precision of the estimated parameters of a distributed-lag model. The technique constrains the parameters of each distributed lag to lie on a polynomial of a given degree. Perhaps because relatively little was known about the procedure when A-J published their paper, critics contended that the $A^{-J}$ results might be dependent upon, or at least sensitive to, their choice of lag length or polynomial degree:"s

There have been relatively few investigations of this aspect of the A-J equation. The best-known study by Schmidt and Waud (1973), as well as others by Corrgan, de Leeuw and Kalchbrenner, and silber, focused primarily on the selection of the lag length. Because these studies held the polynomial degree fixed, how-

\footnotetext{
${ }^{2} \mathrm{~T}$ The restrictions forced the estimated parameters of each distributed lag to lie on a second degree polynomial.

sMeyer and Rasche (1980), p. 59. McCallum (1986), p. 14 , simply notes that "if there is a fiscal policy measure that carries a strongly significant sum of coefficients in an equation of the St. Louis form, its existence has not been well publicized."

30 Specifically, if the lag tength is too long of the polynomial degree too high, estimated parameters are unbiased but inefficient. Alternatively, if the lag length is too short or the polynomial degree is too low, the estimates are biased. Therefore, it is important that the approprate lag length and polynomial degree be determined. The parameters will also be biased if the chosen lag is too long and exceeds the true lag by more than the true polynomial degree and may be biased even if it exceeds the true lag by an amount less than or equal to the true polynomial degree. See Batten and Thornton (1983) for a discussion of this and other issues, and for other references.
} 
ever, they did not analyze completely the restrictions imposed by the A-J specification."

When Elliot (1975) examined the lag structure and the polynomial restrictions separately, he concluded that $A-J$ results were not particularly sensitive to lag structure or to the polynomial restrictions. His conclusion, however, was not based on statistical tests. He merely compared parameter estimates for different lag structures and polynomial degrees. More recently, Batten and Thornton (1983) perfomed a systematic examination of the specification of the A-J equation using recent data, and Batten and Thornton (1985) performed a similar analysis using the original $A-J$ data. They concluded that the policy-felevant results of A-J do not depend on their choice of lag length or polynomial degree.

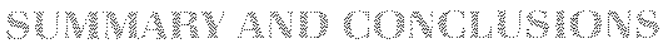

Leonall C. Andersen's best known and most significant contribution to economics is his collabotative research with Jerty l.. Jordan, which resulted in publim cation of the A-J equation. For a period of nearly 20 years, it has been the subject of much interest and considerable criticism.: Few other pieces of applied economics, if any, have been so thoroughly discussed, analyzed and investigated.

Our review of the original Andersen-Jordan study and the criticism that emerged following its publication points out the obvious, but seldom articulated, fact that all of the criticisms of Andersen and Jordan's work apply equally well to much of the applied economie research of that time, and even today. We also note that Andersen and Jordan were aware of many of the caveats of their work and took precautions against them. Most importantly, using their original data, we tested the Andersen-Jordan equation for misspecification and simultaneous equation bias. We find that none of the oft-cited criticisms of their equation is for could have been substantiated by these statistical tests. Granted, some of the techniques used were unknown or unavailable when Andersen and Jordan's critics were most vocal. Furthemore, some of the criticisms are valid when applied to sample periods beyond that examined by Andersen and Jordan.: These facts notwithstanding, this review vindicates Andersen and Jordan of any serious breach of the standards of econometric practice and suggests that, in reality, it was not their application of econometric methods that was controversial, but their results.

Andersen and Jordan should be congratulated for providing one of the most stable, lasting and robust equations in applied economics. In our opinion, however, their most important contribution is that they shook the foundations of conventional economic thought and subjected the resuts of standard applied economics to closer scrutiny. This forced economists and policymakers to take a closer look at the issue of the efficacy of monetary and fiscal policy.

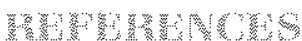

Almon, Shirley. "The Distributed Lag Between Capital Appropriations and Expenditures," Econometrica (January 1965), pp. 17896.

Andersen, Leonall C. "Money Market Conditions as a Guide for Monetary Management," in Karl Brunner, ed., Targets and Indicators of Monetary Policy (Chandler, 1969).

Andersen, Leonall $C$., and Jerry L. Jordan. "Monetary and Fiscal Actions: A Test of Their Relative Importance in Economic Stabillzation - Reply," this Review (April 1969), pp. 12-16.

"Monetary and Fiscal Actions: A Test of Their Relative Importance in Economic Stabilization," this Review (November 1968), pp. 11-24.

Batten, Dallas S., and Daniel L. Thornton. "The Andersen-Jordan Equation Revisited," Joumal of Macroeconomics (Summer 1985), pp. 419-32

"Polynomial Distributed Lags and the Estimation of the St. Louis Equation," this Review (April 1983), pp. 13-25.

Blinder, Alan S., and Robert M. Solow. "Analytical Foundations of Fiscal Policy," in The Economics of Public Finance (Brookings Institution, 1974), pp. 3-115.

Carlson, Keith M. "Does the St. Louis Equation Now Belleve in Fiscal Policy?" this Review (February 1978), pp. 13-19.

\footnotetext{
${ }^{31}$ After the polynomial degree has been chosen, alternative lag specifications amount to imposing polynomial restrictions on differen: parameter spaces. Consequently, the restrictions implied by different lag specifications are not nested withir each other when the polynomial degree is fixed.

${ }^{32}$ One of the most recent additions to this fiterature, Raj and Siklos (1986). applies spectral analysis to the Andersen-Jordan equation for the period $/ / 1947$ to IV/1984. Again the results are consistent with those of A-J.
}

\footnotetext{
${ }^{33}$ For example, Thornton and Batten (1985) find bidirectional Granger causality between money and income over the period from Il/1962 to $11 / 1 / 1982$

34t is irteresting to note the similitarities between the A-J equation and Granger's (1969) and Sims' (1972) examination of causal ordering. Furthermore, except for the exclusion of the own distributed lag of the dependent variable, the A-J equation closely resembles the now frequently used and commonly accepted vector autoregression model.
} 
Chow, Gregory C. "On the Long-Run and Short-Run Demand For Money," Joumal of Political Economy (April 1966), pp. 111-31.

Cooley, Thomas F., and Stephen F. LeRoy. "Identification and Estimation of Money Demand," American Economic Review (De. cember 1981), pp. 825-44

Corrigan, E. Gerald. "The Measurement and Importance of Fiscal Policy Changes," Federal Reserve Bank of New York Monthy Review (June 1970), pp. 133-45.

Darby, Michael R. "Comments on Modigliani and Ando," in Jerome L. Stein, ed., Monetarism, vol. 1, Studies in Monetary Economics (North-Holland, 1976), pp. 67-68.

Davis, Richand G. "How Much Does Money Matter? A Look at Some Recent Evidence." Federal Reserve Bank of New York Monthly Review (June 1969), pp. 119-31.

de Leeuw, Frank, and John Kalchbrenner. "Monetary and Fiscal Actions: A Test of Their Relative Importance in Economic Stabifization - Comment," this Review (April 1969), pp. 6-11.

Duesenberry, J. S., G. Fromm, L. R. Klein, and E. Kuh, eds. The Brookings Quarterly Econometric Model of the United States (RandMcNally, 1965).

Elliott, J. W. "The Infuence of Monetary and Fiscal Actions on Total Spending," Joumal of Money, Credit, and Banking (May 1975), pp. $181-92$.

Feige, Edgar L., and Douglas K. Pearce. "The Casual Causal Relationship Belween Money and income: Some Caveats for Time Series Analysis," Review of Economics and Statistics (November 1979), pp. 521-33.

Friedman, Benjamin M. "Even the St. Louis Model Now Believes in Fiscal Policy," Journal of Money, Credit, and Banking (May 1977), pp. $365-67$.

Friedman, Mitton, and David Meiselman. "The Relative Stability of Monetary Velocity and the Invesiment Multiplier in the United States, 1897-1958," in The Commission on Money and Credit, Stabilization Poficies (Prentice-Hal, 1963), pp. 165-268.

Fomby, Thonas B., R. Carter Hill, and Stanley R. Johnson. Advanced Econometric Methods (Springer-Verlag, 1984).

Gordon, Robert J. "Comments on Modigliani and Ando," in Jerome L. Stein, ed., Monetarism, vol. 1, Studies in Monetary Economics (North-Holland, 1976), pp. 52-66.

Gramlich, Edward M. "The Usefulness of Monetary and Fiscal Policy as Discretionary Stabitization Tools," Joumal of Money, Credit, and Banking (May 1971), pp. 506-32.

Granger, Clive W. J. "Investigating Causal Relations by Econometric Modess and Cross-Spectral Methods," Econometrica (July 1969), pp. 424-38.

Klein, L. R. "Comments on Modigliani and Ando," in Jerome L. Stein, ed., Monetarism, vol. 1, Studies in Monetary Economics (North-Holland, 1976), pp. 50-51.
McCallum, Benneti T. "Monetary Versus Fiscal Policy Effects: A Review of the Debate," in R. W. Hafer, ed., The Monetary Versus Fiscal Policy Debate: Lessons From Two Decades, Studies in Monetary and Macroeconomic Theory and Policy (Rowman and Allanheld, 1986), pp. 9-29.

"A Reconsideration of Sims' Evidence Concerning Monetarism," Economic Letters (vol. 13, nos. 2-3, 1983), pp. 167 71.

Meyer, Lawrence H., and Robert H. Rasche. "Empirical Evidence on the Effects of Stabilization Policy," in Stabilization Policies: Lessons from the '70s and Implications for the '80s (Washington University in St. Louis, Center for the Study of American Business, Working Paper No. 53, 1980), pp. 41-112.

Modigliani, Franco, and Albert Ando. "Impacts of Fiscal Actions on Aggregate Income and the Monetarist Controversy: Theory and Evidence," in Jerome L. Stein, ed., Monetarism, vol. 1, Studies in Monetary Economics (North-Holland, 1976), pp. 17-42.

Raj, Baldev, and Pierre L. Siklos. "The Role of Fiscal Policy in the St. Loulis Model: An Evaluation and Some New Evidence," Joumal of Applied Econometrics (1986), pp. 287-94.

Ramsey, James B., and Peter Schmidt. "Some Further Results on the Use of OLS and BLUS Residuals in Specification Error Tests," Joumal of the American Statistical Association (June 1976), pp. 389-90.

Schmidt, Peler, and Roger N. Waud. "The Aimon Lag Technique and the Monetary Versus Fiscal Policy Debate," Journal of the American Statistical Association (March 1973), pp. $11-19$.

Schwartz, Anna J. "Comments on Modigliani and Ando," in Jerome L. Stein, ed., Monetarism, vol. 1 . Studies in Monetary Economics (North-Holland, 1976), pp. 43-49.

Silber, William 1., "The St. Louis Equation: 'Democrattc' and 'Republican' Versions and Other Experiments." Review of Economics and Statisfics (November 1971), pp. 362-67.

Sims, Christopher A. "Policy Analysis with Econometric Models", Brookings Paper on Economic Activity (1: 1982), pp. 107-52.

"Comparison of Interwar and Postwar Business Cycles: Monetarism Reconsidered" American Economic Aeview (May 1980), pp. 250-57.

"Money, Income, and Causality," American Economic Review (September 1972), pp. 540-52.

Thomton, Daniel L., and Dallas S. Batten. "Lag-Length Selection and Tests of Granger Causality Between Money and Income," Journal of Money, Credit, and Banking (May 1985), pp. 164-78.

Wu, De-Min. "Tests of Causality, Predeteminedness and Exogeneily," International Economic Review (October 1983), pp. 547-58.

"Alternative Tests of Independence Between Stochastic Regression and Disturbances," Econometrica (July 1973). pp. $733-50$. 